\title{
Building Energy Simulations at Urban Scale Based on Standardized Data Models Using a Transparent Enrichment Process
}

\author{
Andreas Geiger ${ }^{1}$, Joachim Benner ${ }^{1}$, Karl-Heinz Häfele ${ }^{1}$, Veit Hagenmayer ${ }^{1}$ \\ ${ }^{1}$ Karlsruhe Institute of Technology, \\ Institute for Automation and Applied Informatics, Karlsruhe, Germany
}

\begin{abstract}
A fundamental problem to perform reliable energy simulation on urban level is that available data from statistics or cadastral agencies is not sufficient. To perform an energetic simulation based on such data, each simulation tool has its own strategies to enrich the data with missing, energy relevant information. In most cases, these enrichment mechanisms are not transparent for the user and the obtained results are strongly dependent on the used tool. The present paper describes a new approach to achieve more transparency in analysing the energetic performance of buildings on urban scale. Thereby a transparent enrichment process based on the standardized 3D city model CityGML and its energy-related extension (EnergyADE) is used. Basic concepts of this process and its implementation with two building energy simulation systems are described.
\end{abstract}

\section{Introduction}

In the report "Energy and Air Pollution" of the International Energy Agency (IEA), it has been shown that cities are responsible for more than $70 \%$ of greenhouse gas emissions (IEA, 2016). This highlights the need for reduction of energy demand and $\mathrm{CO} 2$ emissions at urban scale, and at the same time for increasing the usage of renewable energies in cities. To achieve these goals, new holistic urban planning approaches are necessary, considering all aspects of sustainable urban development.

A significant fraction of the overall energy consumption of cities is caused by thermal energy demands of buildings. Over the past few years, a number of simulation frameworks, libraries and tools have been developed and are used for calculating the thermal behaviour of buildings on urban scale. In this context three categories of software tools can be distinguished:

- Building energy simulation tools

- Urban energy simulation applications

- Simulation libraries

In the area of energy simulation tools for single buildings, a lot of commercial software packages (like ETU Gebäude-Simulation 3D PLUS, EQUA IDA ICE, IES Virtual Environment, TRNSYS) are available. In addition, the open source simulation kernel EnergyPlus funded by the U.S. Department of Energy offers a building energy simulation program for practitioners and researchers.
In contrast, building simulation on urban scale is still mostly performed in the academic area where tools like SimStadt (Nouwel et al., 2015), CitySim (Robinson et al., 2009), SUNSHINE (Giovannini et al., 2014) have been developed. A professional version of CitySim is offered by the company kaemco LLC, Switzerland.

Especially in the academic and research area, building simulation libraries for Modelica and Matlab are popular. Example for such libraries are the Modelica Library AIXLIB (Fuchs et al., 2015), the Modelica Buildings library (Wetter et al., 2014), the Modelica BuildingSystems library (Nytsch-Geusen et al., 2014) and SIMBAD building model for the MATLAB/SIMULINK environment (Khoury et al., 2005).

To perform a thermal simulation for a single building, it might be possible to enter the building parameters for the simulation manually. In a more advanced process the most relevant parameters can be taken from a building information model (BIM). IFC (Industry Foundation Classes) (ISO 16739:2018) is the most frequently used general BIM. Data models specifically designed for energy applications are the Green Building XML (gbXML) model (gbXML, 2019) and the SimModel (Cao et al., 2014), (Cao, 2018). Though these data models are able to represent an arbitrary number of buildings, they are mostly used to describe a single building.

The focus of thermal simulations of single buildings is typically a multi zone approach with regard of selfshading, while on city level the building details are much lower and single zone calculations are performed. For these analyses also neighbouring buildings, the vegetation and in some cases heat island or microclimatic effects should be considered.

The biggest challenge to perform thermal simulations on urban level is to get the energy relevant information. Typical sources for urban wide building information are 2D cadastre data or virtual 3D city models, usually represented in CityGML (Gröger et al., 2012). This data is generally available from public agencies and typically contains the building's position, a more or less generalized geometry and a differentiation of the outer surfaces into the elements roof, wall and ground slab. Further energy relevant information is not available. Therefore, all of the above mentioned urban energy simulation systems have own specific strategies for checking, correcting and enriching the available information - and transforming it into an internal 
simulation model. Usually, these internal enrichment processes are tool specific and not transparent to the user and not part of the displayed simulation results.

For representing buildings and other city objects, the Open Geospatial Consortium (OGC) standard City Geography Markup Language (CityGML) (Gröger, 2012) was published in 2008. CityGML covers basic building information and is intended to be extended for special requirements. Therefore the model offers a mechanism to extend the model schema (Application Domain Extension, ADE). With the development of the Energy Application Domain Extension for CityGML (CityGML Energy ADE) a "neutral" data model is available, which can be used as an interface between Building Information Modelling (BIM) tools and Geographic Information Systems (GIS) on the one hand and building energy simulation tools on the other hand.

In the present paper, a transparent workflow based on two newly developed software modules is described. The workflow in general is based on the common information model CityGML for the representation of 3D urban objects. It defines the classes and relations for the most relevant topographic objects in cities and regional models with respect to their geometrical, topological, semantical, and appearance properties. Geometrically, these objects can be represented in five different Levels of Detail (LoD0 - LoD4). The described workflow supports LoD2 as well as LoD3. In order to support energy-specific information, the CityGML extension Energy ADE is used.

The first module enriches a CityGML LoD2 or LoD3 data set with energy related information and stores the results as CityGML Energy ADE model. The second module supports building energy simulations with existing tools, based on Energy ADE models. The proof of concept of this new approach, which consists in using a uniform neutral data model as a starting point for the energetic simulation with different systems, is demonstrated by a test case with four non-residential buildings.

The present paper is organized as follows: first background information to the CityGML extension Energy ADE is provided, afterwards the developed workflow - based on the two software modules - is described and finally, the simulation results are discussed on the basis of a small data set.

\section{CityGML Energy ADE}

The OGC standard CityGML provides a data model for describing virtual 3D cities. It is subdivided into different modules, among which the building module is the most important one. CityGML has not been designed to cover domain-specific aspects. Thus, the model allows for extending the base schema by new features and properties (van den Brink et al., 2013). These domain-specific extensions are called CityGML Application Domain Extension (ADE). Among other ADEs (Biljecki et al., 2018), the CityGML Energy ADE with version 1.0 (EnergyADE, 2018) is the most advanced extension.
The Energy ADE supports detailed energy simulations of single buildings, as well as global estimations of the energetic behaviour of multiple buildings. For this, it extends the CityGML Building object with energy relevant properties, and relations to one or more thermal zones and corresponding usage zones. Additional properties for the building are for example the building type, the construction weight and numerical values for the building volume and the floor area.

The thermal zones are bounded by thermal boundaries, which can by classified according to the construction type (e.g. wall, roof). Thermal boundaries may have thermal openings and a reference to the component construction including material properties.

Usage zones, which are referenced by thermal zones, prescribe arbitrary schedules for heating, cooling and ventilation as well as internal gains due to occupants and equipment (Agugiaro et al., 2018, Benner et al., 2016).

In addition, the Energy ADE allows for modelling energy conversion, distribution, storage and emission devices and the energy flow between them. This enables energy demand and supply analyses, $\mathrm{CO} 2$ emission calculations and primary energy balances (Agugiaro et al., 2018).

\section{Building Energy Simulation Workflow}

The new energy simulation workflow presented in the following is divided into two steps. Each of these steps is realized by a separate software module which can be used independently. The first module enriches a CityGML data set transparently with energy related information and stores the results in Energy ADE format. The second module processes one or more Energy ADE data sets for performing thermal simulations with existing energy simulation tools.

\section{Transparent Data Enrichment}

The new transparent enrichment process operates on one or many CityGML building models (CityGML object Building) with LoD2 or LoD3 geometry. Since such models do not contain information concerning the building's interior structures, the building is regarded as thermally homogeneous. Thus, the new enrichment process always produces a single-zone thermal model.

Every CityGML Building object is enriched separately in six steps:

1. Checking and (if necessary) enhancement or correction of the building geometry.

2. Checking and completion of the set of global building parameters: Building is heated / is cooled, year of construction or last renovation, construction weight, gross volume, net floor area.

3. Assignment of physical and optical parameters to building elements (wall, roof, base slab and window elements): U-value / thermal conductivity, density, heat capacity, thickness, transparency and glazing ratio of windows.

4. Assignment of "window to facade" ratios to all wall and roof elements (this step is only needed for LoD2 models). 
5. Specification of time profiles for heating and cooling set-point temperatures, by defining 24 hourly values for specific days of the week like, e.g., weekdays and weekend days.

6. Specification of parameters and time profiles (see above) to model internal heat gains/losses due to occupants, lighting, electrical devices and ventilation.

The first process step is always executed automatically by using suited geometric algorithms, mainly to make sure that the geometric building parameters needed for a thermal simulation (e.g. building volume, as well as position, size and orientation of external boundary surfaces) can be derived reliably from the CityGML data. A central point in this context is the detection of overlapping boundary surfaces, which is discussed in detail in (Geiger 2018).

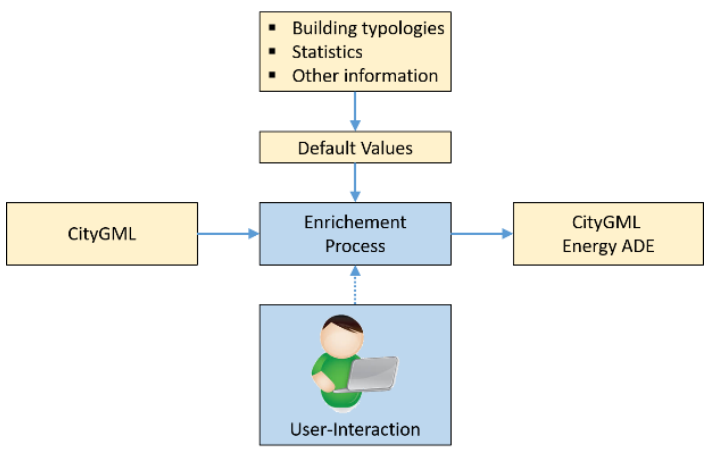

Figure 1: Overview of transparent enrichment process

All other process steps can be executed either automatically or under user control (see Figure 1). In both cases, at the beginning of each process step, the software proposes plausible assumptions for the missing parameters. These assumptions are based on geometric and attributive information available in the CityGML data, supplemented by externally available default values and statistical information.

In the automatic enrichment mode, the software directly uses the generated proposals. Otherwise, the proposed enrichment data are presented to the user for checking, correction and completion. At the end of the process, all enrichment parameters are collected and, together with the CityGML input data, exported as Energy ADE data set.

\section{Thermal simulation based on Energy ADE data}

The second module is designed to perform thermal simulations of buildings with existing simulation systems on base of a CityGML Energy ADE model. The basic concept is depicted in Figure 2: Energy ADE data is transformed into input data for a specific simulation system, the simulation is started and monitored, and finally the results are visualized and optionally stored in the Energy ADE data set. Currently, the module supports the two simulation systems EnergyPlus and ETU GebSim (see Figure 2).

EnergyPlus is a free, open-source, and cross-platform energy analysis and thermal load simulation program. The development of EnergyPlus is funded by the U.S.
Department of Energy's (DOE) Building Technologies Office (BTO).

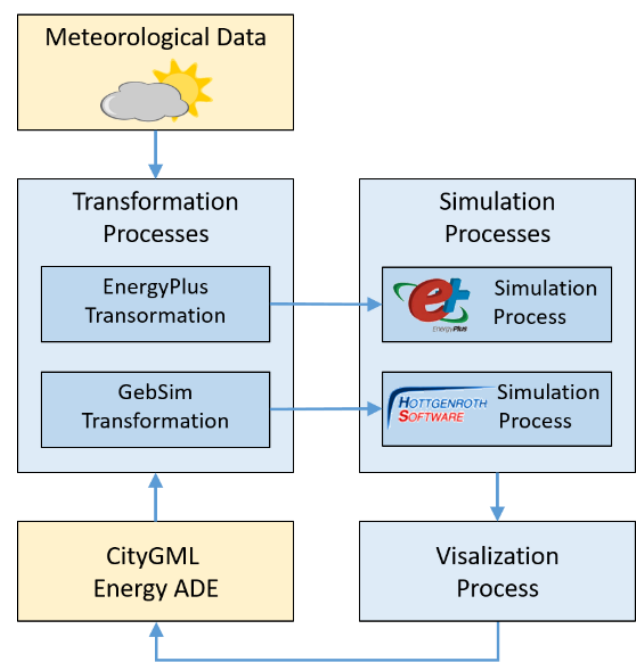

Figure 2: Overview of simulation process

The second system is the commercial simulation software ETU GebSim, developed by the company Hottgenroth software. The system is developed on the calculation bases of the VDI 6007 "Calculation of transient thermal response of rooms and buildings modelling of windows". This simulation system internally uses a data model based on the BIM (Building Information Model) concept and all data is stored on a SQL database.

The transformation process is realized for both simulation systems. As EnergyPlus is a commonly used software tool, this article will focus on generating an EnergyPlus textual input data file (IDF file) from Energy ADE data.

An IDF file contains the needed information (building and HVAC data, simulation parameters) to simulate one single building. Therefore, every CityGML Building object in an Energy ADE input file is mapped onto one IDF file, whose name is derived from the Building gml:name property. Table 1 gives an overview how Energy ADE objects are mapped on EnergyPlus objects in this transformation process.

In addition to the EnergyPlus objects depicted in Table 1, the generated IDF file contains a number of objects without counterpart in the Energy ADE data model. This especially concerns the specification of basic simulation parameters (e.g. EnergyPlus objects ShadowCalculation, TimeStep, HeatBalanceAlgorithm) and the specification of ground temperatures by the EnergyPlus object Site:GroundTemperature:BuildingSurface. To model this kind of data in the Energy ADE will be a topic for future developments.

The transformation of Energy ADE objects into EnergyPlus objects in some cases needs an adaptation of existing or generation of new geometry. If an Energy ADE ThermalBoundary has multi-surface geometry, it must be transformed into a simple polygon representation of the EnergyPlus object BuildingSurface:Detailed. Furthermore, in case if an Energy ADE ThermalOpening has no explicit geometry, a rectangular opening geometry 
with the specified size needs to be generated for the EnergyPlus object FenestrationSurface:Detailed.

Table 1: Mapping table Energy ADE to EnergyPlus

\begin{tabular}{|c|c|}
\hline Energy ADE feature & EnergyPlus object \\
\hline ThermalZone & Zone \\
\hline ThermalBoundary & BuildingSurface:Detailed \\
\hline ThermalOpening & FenestrationSurface:Detailed \\
\hline Construction & Construction \\
\hline LayerComponent. & Material \\
SolidMaterial & WindowMaterial:Simple \\
& GlazingSystem \\
\hline LayerComponent.Gas & Material:AirGap \\
\hline UsageZone.HeatingSchedule & HVACTemplate:Thermostat \\
UsageZone.CoolingSchedule & HVACTemplate:Zone: \\
\hline UsageZone.ventilation & $\begin{array}{c}\text { ZoneInfiltration:DesignFlow } \\
\text { Rate }\end{array}$ \\
\hline Schedule & People \\
\hline Occupants & Lights \\
\hline LightingFacilities & ElectricEquipment \\
\hline ElectricalAppliances & Schedule:Compact \\
\hline DailyPatternSchedule & Idirstem \\
\hline Energy ADE is
\end{tabular}

The Energy ADE is principally able to represent meteorological information. In the current implementation this feature is not supported, and meteorological information is integrated via the proprietary data formats of the simulation systems. For ETU GebSim, this is a simple XML format containing hourly values for the following parameters:

- Air temperature,

- Relative air humidity,

- Wind speed,

- Cloudiness

- Direct short-wave radiation

- Diffuse short-wave radiation,

- Long-wave downward atmospheric radiation and

- Terrestrial emission.

These parameters are also used in the EnergyPlus weather data (EPW) format, all additional parameters which could be specified in an EPW file are actually marked as "missing". The transformation between the two input data formats is complicated by the usage of different physical units of measure (e.g. Kilowatt hours vs. Joule for energy) and different reference areas for the direct solar irradiance (horizontal plane vs. a plane normal to the sun's rays at a certain instant of time).

For controlling the simulation process, a single user interface supporting EnergyPlus and ETU GebSim is available. The intended simulation tool can be chosen and the corresponding weather data must be assigned. After the simulation process is complete the results are presented and can be stored in the Energy ADE file.

For the sake of first demonstration, only one type of simulation is supported: Calculating the annual heating and/or cooling demand with a temporal resolution of 1 hour. As results, total annual values as well as hourly time series for a number of simulation result parameters (see Table 2) are available.

Table 2: Examples of simulation result parameters

\begin{tabular}{|c|c|}
\hline Heating energy & $\mathrm{kW}$ \\
\hline $\begin{array}{c}\text { Cooling energy } \\
\text { appliances }\end{array}$ & $\mathrm{kW}$ \\
\hline $\begin{array}{c}\text { Thermal energy gains due to electrical } \\
\text { Thermal energy gains due to lighting }\end{array}$ & $\mathrm{kW}$ \\
\hline Thermal energy gains due to occupants & $\mathrm{kW}$ \\
\hline $\begin{array}{c}\text { Thermal energy gains and losses via windows } \\
\text { Thermal energy gains and losses due to } \\
\text { ventilation and infiltration }\end{array}$ & $\mathrm{kW}$ \\
\hline Zone air temperature & ${ }^{\circ} \mathrm{kW}$ \\
\hline
\end{tabular}

\section{Workflow Testing and Evaluation}

\section{Sample Data}

For testing and evaluating the described approach, 4 building located on the Campus North of the Karlsruhe Institute of Technology (KIT) are chosen. The corresponding CityGML LoD2 models (see Figure 3) originated from the Landesamt für Geoinformation und Landentwicklung, Baden-Württemberg) (LGL-BW, 2018).

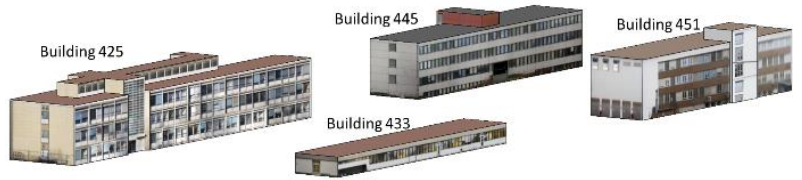

Figure 3: Four test buildings of KIT Campus North

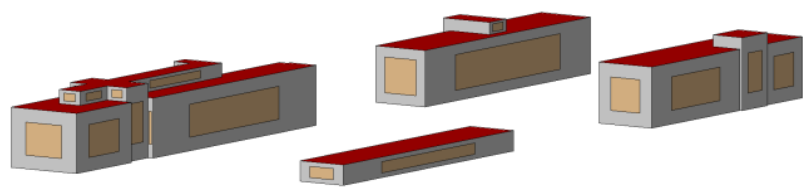

Figure 4: Test buildings with generated windows

Beside a number of generic attributes, the model data contain the CityGML standard attributes function, storeysAboveGround and measuredHeight. The attribute function is defined by a code list from the German standard ALKIS (GDI-DE, 2018).

In the original data set, the Building attribute yearOfConstruction is not defined. Since this property is an important basis for estimating physical parameters of the building like U-Values, it is manually added using information of the KIT facility management department. Table 3 lists the most important geometry parameters of the sample buildings.

Table 3: Building properties

\begin{tabular}{|c|c|c|c|c|}
\hline & $\begin{array}{c}\text { Building } \\
425\end{array}$ & $\begin{array}{c}\text { Building } \\
433\end{array}$ & $\begin{array}{c}\text { Building } \\
445\end{array}$ & $\begin{array}{c}\text { Building } \\
451\end{array}$ \\
\hline function & 3024 & 2020 & 3024 & 3024 \\
\hline roofType & \multicolumn{5}{|c|}{ Flat roof (1000) } \\
\hline storeysAboveGround & 4 & 1 & 4 & 4 \\
\hline
\end{tabular}




\begin{tabular}{|c|c|c|c|c|}
\hline measuredHeight $[\mathrm{m}]$ & 12,947 & 4,360 & 14,017 & 13,009 \\
\hline yearOfConstruction & 1966 & 1977 & 1973 & 1966 \\
\hline Ground area $\left[\mathrm{m}^{2}\right]$ & 1253,3 & 699,912 & 783,594 & 769,488 \\
\hline Wall area $\left[\mathrm{m}^{2}\right]$ & 3191,3 & 648,168 & 1913,71 & 1924,3 \\
\hline Roof area $\left[\mathrm{m}^{2}\right]$ & 1253,3 & 699,912 & 783,594 & 769,488 \\
\hline Gross volume $\left[\mathrm{m}^{3}\right]$ & 17147,4 & 3051,62 & 9608,92 & 10107,1 \\
\hline Net floor area $\left[\mathrm{m}^{2}\right]$ & 4010,56 & 559,92 & 2507,52 & 2462,4 \\
\hline
\end{tabular}

The focus of the present paper is not to simulate the actual energetic performance of buildings, but to prove that different simulation tools can produce comparable results in case they operate on the same building model. For this reason, we simplify the enrichment process by assigning the same parameter to all four buildings. On component level we have - according to LoD 2 of CityGML - the differentiation between wall surfaces, ground surfaces and roof surfaces. The assigned physical properties are shown in Table 4.

Table 4: Materials of the building elements

\begin{tabular}{|c|c|}
\hline U Value wall surfaces $\left[\mathrm{W} / \mathrm{m}^{2} \mathrm{~K}\right]$ & 1,0 \\
\hline U Value roof surfaces $\left[\mathrm{W} / \mathrm{m}^{2} \mathrm{~K}\right]$ & 1,3 \\
\hline U Value ground surfaces $\left[\mathrm{W} / \mathrm{m}^{2} \mathrm{~K}\right]$ & 1,2 \\
\hline Density (all elements) $\left[\mathrm{kg} / \mathrm{m}^{3}\right]$ & 2200 \\
\hline Specific heat capacity [kJ/kgK] & 1 \\
\hline Thickness [m] & 0,2 \\
\hline U Value windows $\left[\mathrm{W} / \mathrm{m}^{2} \mathrm{~K}\right]$ & 1,8 \\
\hline Window to facade ratio [\%] & 30 \\
\hline Glazing ratio [\%] & 80 \\
\hline Glazing transparency [\%] & 60 \\
\hline
\end{tabular}

Beside material properties, the usage profiles provide essential information to perform a thermal simulation. These are assumptions about the use of space, in particular about the occupancy of persons and the use of equipment (see Table 5).

Table 5: Usage profiles office building

\begin{tabular}{|c|c|c|c|}
\hline Heating profile & $\begin{array}{l}0 \mathrm{~h}-5 \mathrm{~h} \\
5 \mathrm{~h}-6 \mathrm{~h} \\
6 \mathrm{~h}-7 \mathrm{~h} \\
7 \mathrm{~h}-18 \mathrm{~h} \\
18 \mathrm{~h}-24 \mathrm{~h}\end{array}$ & $\begin{array}{l}17^{\circ} \mathrm{C} \\
18^{\circ} \mathrm{C} \\
20^{\circ} \mathrm{C} \\
21^{\circ} \mathrm{C} \\
17^{\circ} \mathrm{C}\end{array}$ & Weekday \\
\hline & $0-24$ & $17^{\circ} \mathrm{C}$ & Weekend \\
\hline Cooling profile & \multicolumn{3}{|c|}{ Cooling deactivated } \\
\hline \multirow[t]{2}{*}{ Ventilation profile } & $\begin{array}{l}0 \mathrm{~h}-8 \mathrm{~h} \\
8 \mathrm{~h}-18 \mathrm{~h} \\
18 \mathrm{~h}-24 \mathrm{~h}\end{array}$ & $\begin{array}{l}01 / \mathrm{h} \\
11 / \mathrm{h} \\
01 / \mathrm{h}\end{array}$ & Weekday \\
\hline & $0 \mathrm{~h}-24 \mathrm{~h}$ & $01 / \mathrm{h}$ & Weekend \\
\hline Shading profile & \multicolumn{3}{|c|}{ No shading devices } \\
\hline \multirow[t]{2}{*}{$\begin{array}{l}\text { Lighting Profile } \\
\qquad\left(5 \mathrm{~W} / \mathrm{m}^{2}\right)\end{array}$} & $\begin{array}{l}0 \mathrm{~h}-8 \mathrm{~h} \\
8 \mathrm{~h}-18 \mathrm{~h} \\
18 \mathrm{~h}-24 \mathrm{~h}\end{array}$ & $\begin{array}{r}0 \% \\
50 \% \\
0 \%\end{array}$ & Weekday \\
\hline & $0 \mathrm{~h}-24 \mathrm{~h}$ & $0 \%$ & Weekend \\
\hline
\end{tabular}

\begin{tabular}{|c|c|c|c|}
\hline \multirow[t]{2}{*}{$\begin{array}{c}\text { Occupant Profile } \\
\text { (70 W per Person, } \\
30 \mathrm{~m}^{2} / \text { Person) }\end{array}$} & $\begin{array}{l}0 \mathrm{~h}-8 \mathrm{~h} \\
8 \mathrm{~h}-18 \mathrm{~h} \\
18 \mathrm{~h}-24 \mathrm{~h}\end{array}$ & $\begin{array}{r}0 \% \\
50 \% \\
0 \%\end{array}$ & Weekday \\
\hline & $0 \mathrm{~h}-24 \mathrm{~h}$ & $0 \%$ & Weekend \\
\hline \multirow[t]{2}{*}{$\begin{array}{l}\text { Equipment Profile } \\
\left(7 \mathrm{~W} / \mathrm{m}^{2}\right)\end{array}$} & $\begin{array}{l}0 \mathrm{~h}-8 \mathrm{~h} \\
8 \mathrm{~h}-18 \mathrm{~h} \\
18 \mathrm{~h}-24 \mathrm{~h}\end{array}$ & $\begin{array}{r}0 \% \\
50 \% \\
0 \%\end{array}$ & Weekday \\
\hline & $0 \mathrm{~h}-24 \mathrm{~h}$ & $0 \%$ & Weekend \\
\hline
\end{tabular}

The simulations are performed with weather data representing a "typical year" at the KIT site. The corresponding meteorological time series are generated with the Software Meteonorm (Meteonorm, 2019).

\section{Results}

The simulations are performed based on Energy ADE with the two implemented transformation processes for the four buildings shown in Figure 3. To discuss the results we focus on the yearly heating demand which is depicted in Table 6.

It shows deviations of the simulation results between 24 and 34 percent, which are higher than expected. It is obvious that the two used simulation systems are using different physical models, however, this does not explain these results.

Table 6: Yearly heating demand of the test buildings

\begin{tabular}{|c|c|c|c|c|}
\hline & $\begin{array}{c}\text { Building } \\
425\end{array}$ & $\begin{array}{c}\text { Building } \\
433\end{array}$ & $\begin{array}{c}\text { Building } \\
445\end{array}$ & $\begin{array}{c}\text { Building } \\
451\end{array}$ \\
\hline $\begin{array}{c}\text { EnergyPlus } \\
\text { Heating [kWh] }\end{array}$ & 382.227 & 116.180 & 211.165 & 228.490 \\
\hline $\begin{array}{c}\text { ETU GebSim } \\
\text { Heating [kWh] }\end{array}$ & 511.797 & 144.013 & 274.164 & 306.915 \\
\hline Deviation [\%] & 33,90 & 23,96 & 29,83 & 34,32 \\
\hline
\end{tabular}

In the chart of Figure 5 the yearly heating demand in a weekly resolution is shown. The time series of EnergyPlus and ETU GebSim show a very similar behaviour of the two systems.

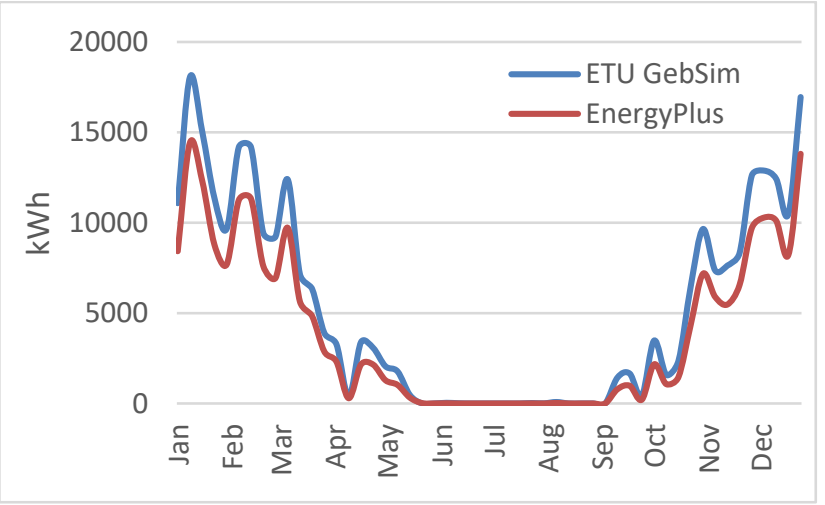

Figure 5: Yearly heating demand (weekly resolution)

In the detailed chart of Figure 6-showing two randomly extracted consecutive days - this behaviour of the two systems can be seen more clearly. At the present time it is still unclear how this deviation can occur. It cannot be excluded that there are still errors in the current implementation of the transformation processes, either for EnergyPlus or for ETU GebSim. This has to be reflected in further analyses. 


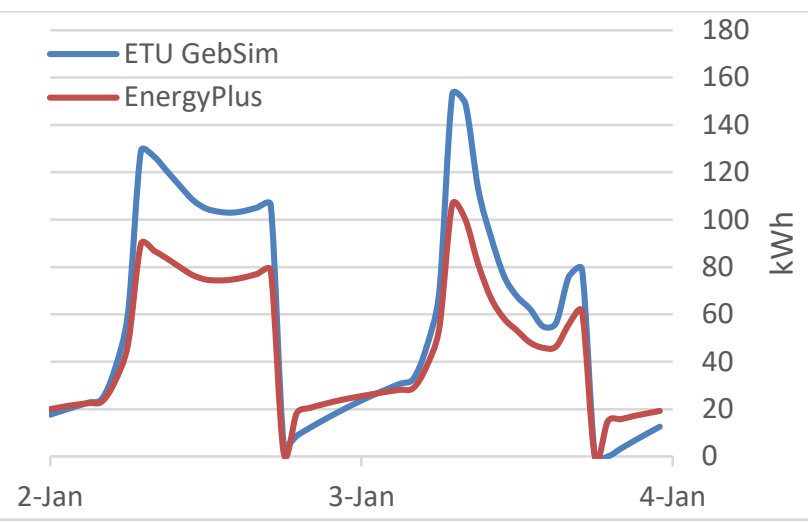

Figure 6: Two days in an hourly resolution

\section{Conclusion and Outlook}

The present paper introduces a new unique transparent workflow to perform thermal energy simulations based on the CityGML Extension Energy ADE at urban scale. This workflow is separated into a transparent enrichment process and a simulation process. Both processes can be executed independently of each other. The first process transforms and enriches transparently a CityGML input data set with energy relevant data, and all data is stored in an Energy ADE file. The second process transforms the Energy ADE data into simulation specific data for thermal analysis tools and performs the simulation. Finally the results are optionally stored in the Energy ADE input file. To verify this new transparent workflow, an implementation with the two different simulation systems - EnergyPlus und ETU GebSim - is realized. It is shown that the Energy ADE can be used as a neutral input data format for different simulation tools. However, the difference of the two simulation system's results obtained for the same input data model is higher than expected. Though the diurnal variations of the calculated heating demand values is consistent, the EnergyPlus simulation calculates a significantly lower overall heating demand. There are several potential sources for this discrepancy, which need to be analysed in future work. Besides hypothetical implementation errors in the transformation modules, differences between the physical models used in the two simulation tools may be the reason. One example for this reason is the energy exchange between building and soil, which is not considered in the GebSim system. Furthermore, it turns out that both tools use internal parameters, e.g. internal and external convection coefficients, which are not yet regarded by the Energy ADE. If it can be shown that these physical effects and corresponding parameters significantly influence the simulation results, they must be modelled in future versions of the Energy ADE in order to further improve this important CityGML ADE.

\section{Acknowledgement}

The authors would like to thank the Hottgenroth Software $\mathrm{GmbH} \&$ Co. KG / ETU Software GmbH for providing the "Gebäude-Simulation 3D Plus" Module for the IFCExplorer software.

\section{References}

AdV. (2018). Working Committee of the Surveying Authorities of the Laender of the Federal Republic of Germany. Homepage. http://www.advonline.de/Startseite/. last access December 2018

Agugiaro, G., Benner, J., Cipriano, P and Nouvel, R. (2018). The Energy Application Domain Extension for CityGML: enhancing interoperability for urban energy simulations. Open Geospatial Data, Software and Standards. 3:2 https://doi.org/10.1186/s40965018-0042-y.

Benner, J., Geiger, A., Häfele, K.-H. (2016). Virtual 3D City Model Support for Energy Demand Simulations on City Level - The CityGML Energy Extension. Proceedings REAL CORP 2016. Hamburg.

Biljecki, F., Kumar, K., Nagel, C. (2018). CityGML Application Domain Extension (ADE): overview of development, Open Geospatial Data, Software and Standards (2018) 3:13 Springer Open https://doi.org/10.1186/s40965-018-0055-6.

Cao, J.,Maile, T., O’Donnell, J., Wimmer, R., van Treeck, C. (2014). Model transformation from SimModel to Modelica for building energy performance simulation. Proceedings of the $5^{\text {th }}$ German-Austrian IBPSA Conference, pages 242-249.

Cao, J. (2018). SimModel Transformation Middleware for Modelica-based Building Energy Modeling and Simulation, $\mathrm{PhD}$ thesis, Institute of Efficiency and Sustainable Building E3D, RWTH Aachen University, February 2018.

Crawley, D. B., Pedersen, C. O., Lawrie, L. K., Winkelmann, F. C. (2000) EnergyPlus: Energy Simulation Program. ASHRAE Journal, 42 (4) (2000), pp. 49-56.

Crawley et al. (2001). EnergyPlus: creating a newgeneration building energy simulation program. Energy and Buildings, 33 (4) (2001), pp. 319-331.

EnergyADE. (2018). CityGML Energy ADE - UML Diagram, Schema, Feature Catalogue and Examples. http://www.citygmlwiki.org/index.php?title=CityGM L_Energy_ADE. last access December 2018.

Fuchs et al. (2015). Structuring the building performance modelica library AixLib for open collaborative development. Proceedings of BS2015.

GDI-DE. (2018). Repository of the Geodateninfrastruktur Deutschland (GDI-DE). AdV-CityGML-Codelisten. http://repository.gdi-

de.org/schemas/adv/citygml/Codelisten/. last access January 2019.

Geiger, A., Benner, J., Häfele. K.-H., and Hagenmeyer, V. (2018). Thermal Energy Simulation of Buildings based on the CityGML Energy Application Domain Extension. In: Tagungsband der 7. DeutschÖsterreichischen IBPSA-Konferenz BauSIM 2018, Karlsruhe (2018) 
Giovannini, L., Pezzi, S., Di Staso, U., Prandi, F., De Amicis, R. (2014). Large-Scale Assessment and Visualization of the Energy Performance of Buildings with Ecomaps. In Proceedings of 3rd International Conference on Data Management Technologies and Applications (DATA 2014).

gbXML. (2019). http://gbxml.org/. last access January 2019.

Gröger, G., Kolbe, T.H., Nagel, C., Häfele, K.H. (2012). OGC City Geography Markup Language (CityGML) Encoding Standard. Open Geospatial Consortium Inc., 2012.

Hottgenroth Software. (2019). Gebäude-Simulation 3D PLUS. Website: https://www.etusoftware.com/L/BuildingSimulation/Seite.html,68750,96656.

IEA. (2016). Energy and air pollution - World energy outlook 2016 special report. Organisation for Economic Co-operation and Development / International Energy Agency.

ISO 16739:2018. (2018). Industry Foundation Classes (IFC) for data sharing in the construction and facility management industries -- Part 1: Data schema.

Khoury, Z., Riederer, P., Couillaud, N., Simon, J., Raguin, M. (2005). A Multizone Building Model FOR MATLAB/SIMULINK ENVIRONMENT. Ninth International IBPSA Conference, Montreal, Canada, August 15-18, 2005.

LGL-BW. (2018). Produktverzeichnis Karten, Geodaten, Luftbilder. https://www.lgl-bw.de/lgl-internet/web/
sites/default/de/07_Produkte und_Dienstleistungen/ Galerien/Dokumente/Produktverzeichnis.pdf. last access December 2018.

Meteonorm. (2018). Website: https://meteonorm.com/en/ meteonorm-timeseries. last access January 2019.

Nouvel, R., Brassel, K-H, Bruse, M., Duminil, E., Coors, V., Eicker, U., Robinson, D. (2015). SimStadt, a new workflow-driven urban energy simulation platform for CityGml city models. CISBAT International Conference 2015. Lausanne.

Nytsch-Geusen, C., Mucha, K., Inderfurth, A., Rädler, J. (2014). Entwicklung eines räumlich und physikalisch adaptiven energetischen Gebäudemodells in Modelica. Fifth German-Austrian IBPSA Conference RWTH Aachen University, 2014.

Robinson, D., Haldi, F., Kämpf, J., Leroux, P., Perez, D., Rasheed, A., Wilke, U. (2009). CitySim: Comprehensive Micro-Simulation of Resource Flows for sustainable urban planning. Proceedings of BS2009.

van den Brink L, Stoter J, Zlatanova S. (2013). UMLbased approach to developing a CityGML application domain extension. Trans GIS. 2013;17(6):920-42.

Wetter, M., Zuo, W., Nouidui, T. S., Pang, X. (2014). Modelica Buildings library. Modelica Buildings library. Journal of Building Performance Simulation. 7:4, 253-270, DOI:10.1080/19401493.2013.765506. 